\title{
Familial focal epilepsy with variable foci
}

INSERM

\section{Source}

INSERM. (1999). Orphanet: an online rare disease and orphan drug data base. Familial focal epilepsy with variable foci. ORPHA:98820

Familial focal epilepsy with variable foci is a rare genetic epilepsy disorder characterized by autosomal dominant lesional and nonlesional focal epilepsy with variable penetrance. Focal seizures emanate from different cortical locations (temporal, frontal, centroparietal, parietal, parietaloccipital, occipital) in different family members, but for each individual a single focus remains constant throughout lifetime. Seizure type (tonic, tonic-clonic or hyperkinetic) and severity varies among family members and tends to decrease (but do not disappear) during adulthood. Many patients have an aura and show automatisms during diurnal seizures whereas others have nocturnal seizures. Most individuals are of normal intelligence but patients with intellectual disability, autistic spectrum disorder and obsessive-compulsive disorder have been described. 